\title{
$+1$ \\ AN INNOVATIVE DRESSING FOR A BURN CAUSED WHEN A CELLPHONE EXPLODED WITH USE OF A EPICYTE HYDRO DRESSING.
}

\author{
SERRA M.C. ${ }^{1}$; BOLGIANI A ; ARDILA A.P. ${ }^{3}$; DAHER I ${ }^{4}$; ARRABELLA B.T. ${ }^{3}$
}

1 Specialist in Pediatrics and Intensive Care Medicin, Head of HMSA Burn Treatment Center 2003-2015, Past president of FELAQ, ${ }^{2}$ Head of Burn Treatment Center at Alemán Hospital, Past president of FELAQ, ${ }^{3}$ Plastic surgery resident at the Ivo Pitanguy Institute 4 Plastic surgery and Head of HMSA plastic surgery department plastic of the Souza Aguiar Hospital. - Rio de Janeiro Brasil

\section{Objectives}

To analyse the pain and quantity of time of scarring with use of an Epicyte hydro dressing

\section{Methods}

\section{Clinical case:}

An 11 year old boy who got burned when his cellphone exploded in his pocket while he was playing football. He had an intermediate 2nd degree burn yet he suffered a lot of pain when compared to other patients with this degree of burn. The patient had been received in the Souza Aguiar burns unit 4 days post burn in a lot of pain. His parents did not consent for a skin graft to be used. The dressing he had was carefully removed and Epicyte hydro special dressing was applied where the patient instantly felt relief. The period that the patient remained with the dressings was 7-14 days. He did not need any analgesics and the dressing was needed to be changed three times during this period, as with movement, the dressing would slide leaving the area uncovered.

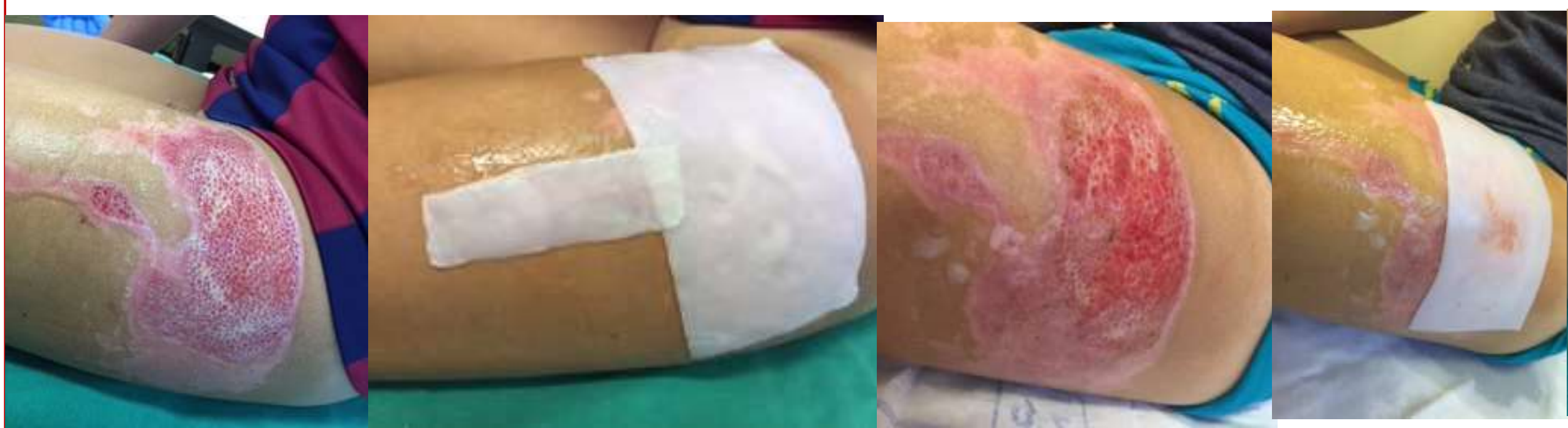

\section{Results}

With difficulties such as calming the parent's anxieties and with fear of pain from the boy, with just 3 dressing changes the scarring had a favorable result.

\section{Conclusion}

Despite this being a difficult case, the Epicyte hydro dressing showed efficiency to facilitate the dressing change, relieve pain and demonstrate scarring of good quality.

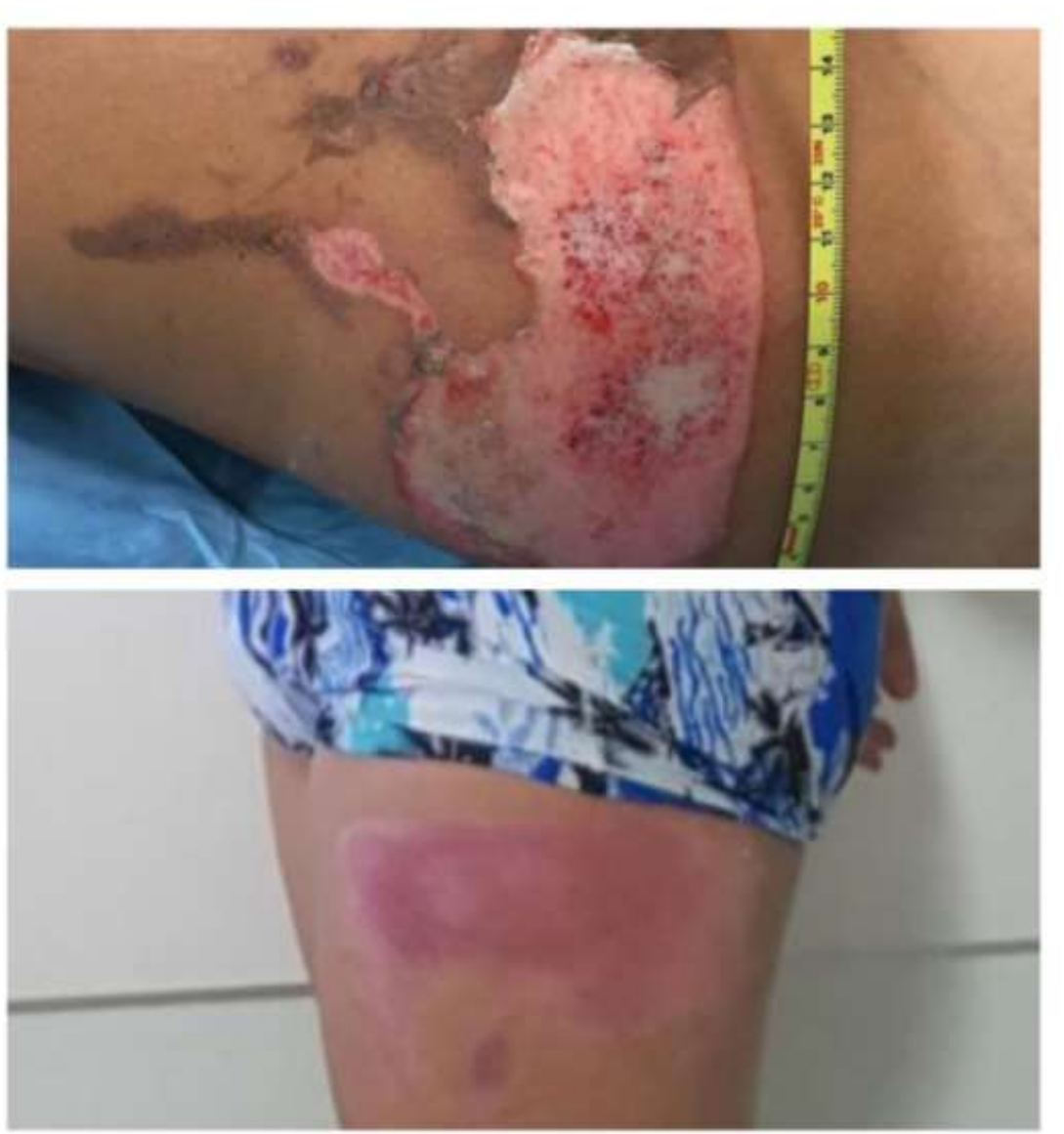

